\title{
Atividades práticas em espaços laboratoriais no ensino de Ciências e Biologia: relatos de uma experiência com estudantes dos anos finais da educação básica da Ilha de São
}

\section{Luís - MA}

\author{
Practical activities in laboratory spaces in the teaching of Science and Biology: reports of an \\ experience with students in the final years of basic education in Ilha de São Luís - MA
}

Actividades prácticas en espacios de laboratorio de enseñanzas de Ciencia y Biología: relatos de una experiencia con estudiantes de los últimos años de educación básica en Ilha de São Luís - MA

\section{Resumo}

Os laboratórios são espaços de construção de boa parte do conhecimento científico biológico. Quando usados no ensino oferecem oportunidades de aproximação dos estudantes da educação básica com a produção científica, despertando nos jovens o interesse pela ciência. Neste trabalho buscamos aproximar os estudantes dos anos finais da educação básica do Laboratório de Genética e Biologia Molecular Warwick Kerr (LABWICK) da Universidade Estadual do Maranhão e também investigamos como esses estudantes percebem as atividades práticas laboratoriais no ensino de ciências e biologia. Para tal, o trabalho contou com três fases: diagnóstico das vivencias laboratoriais dos estudantes em sua escola, visita ao LABWICK, diagnóstico da aprendizagem após a visita. O diagnóstico inicial foi realizado em 12 escolas localizadas na ilha de São Luís -MA, e foi realizado através da aplicação de um questionário (199 estudantes) e de observação in loco. Na fase de visitas ao LABWICK, 9 escolas participaram de palestras e aulas práticas. Todos os estudantes que participaram da visita (226) responderam ao questionário diagnóstico da aprendizagem. Observou-se o interesse e a assimilação de conteúdos pelos alunos no ambiente laboratorial, assim como os relatos quanto a ausência deste tipo de atividade dentro do ambiente escolar. Tais observações apontam para 
a necessidade de ampliar a utilização dos espaços laboratoriais na busca de aulas de ciências dinâmicas e interessantes.

Palavras-chave: Genética; Jovens; Educação; Ensino de Ciências e Biologia; Alfabetização científica.

\begin{abstract}
Laboratories are spaces of construction of a good part of biological scientific knowledge. When used in teaching, they offer opportunities to bring basic education students closer to scientific production, awakening interest in science in young people. In this work we aimed to approach the students of the final years of basic education to the Warwick Kerr Genetics and Molecular Biology Laboratory (LABWICK) of the Universidade Estadual do Maranhão and investigate the perceptions of these students about practical laboratory activities in science and biology classes. To this end, the work had three phases: diagnosis of the laboratory experiences of students at their school, visit to the, diagnosis of learning during the visit. The initial diagnosis was carried out in 12 schools located on the island of São Luís -MA, and was carried out through the application of a questionnaire (199 students) and on-site observation. During the visits to LABWICK, 9 schools participated in lectures and practical classes. All students who participated in the visit (226) answered the learning diagnostic questionnaire. It was observed the interest and assimilation of content by students in the laboratory environment, as well as reports on the absence of this type of activity within the school environment. Such observations point to the need to expand the use of laboratory spaces in the search for dynamic and interesting science classes.
\end{abstract}

Keywords: Genetics; Youth; Education; Science and Biology teaching; Scientific literacy.

\title{
Resumen
}

Los laboratorios son espacios para la construcción de buena parte del conocimiento científico biológico. Cuando se utilizan en la docencia, ofrecen oportunidades para acercar los estudiantes de educación básica a la producción científica, despertando el interés por la ciencia en los jóvenes. En este trabajo investigamos cómo los estudiantes de los últimos años de educación básica perciben las actividades prácticas de laboratorio en la enseñanza de las ciencias y la biología. Para ello, el trabajo tuvo tres fases: diagnóstico de las experiencias de laboratorio de los estudiantes en su escuela, visita al Laboratorio de Genética y Biología Molecular Warwick Kerr (LABWICK) de la Universidade Estadual do Maranhão y diagnóstico de aprendizaje durante la visita. El diagnóstico inicial se realizó en 12 escuelas ubicadas en la isla de São Luís -MA y se realizó mediante la aplicación de un cuestionario (199 estudiantes) con observación in situ. Durante las visitas a LABWICK, 9 escuelas participaron de conferencias y prácticas laboratoriales. Todos los estudiantes que participaron de la visita (226) respondieron el cuestionario de diagnóstico de aprendizaje. Se observó el interés y asimilación de contenidos por parte de los estudiantes en el ambiente de laboratorio, así como informes sobre la ausencia de este tipo de actividad dentro del ambiente escolar. Tales observaciones apuntan a la necesidad de ampliar el uso de los espacios de laboratorio en la búsqueda de clases de ciencias dinámicas e interesantes.

Palabras clave: Genética; Juventud; Educación; Enseñanza de las Ciencias e Biología; Alfabetización científica.

\section{Introdução}

Grande parte das investigações em ciências biológicas são desenvolvidas nos laboratórios de centros de pesquisa ou de instituições de ensino superior. Os conhecimentos construídos nestes espaços, bem como a tecnologia gerada, configuramse como um patrimônio da humanidade (Germano \& Kulesza, 2007) e necessitam da valorização e compreensão públicas. No entanto, este conhecimento nem sempre é transposto para o cidadão, ficando restrito ao ambiente científico.

Uma estratégia importante para ampliar o entendimento e a popularização da ciência e da tecnologia é o fortalecimento do ensino destes temas na educação básica. Aulas mais interessantes e contextualizadas incentivam o interesse pelo conhecimento científico e até por uma possível carreira científica. No entanto, verifica-se que os professores sentem certas dificuldades para desenvolver novas propostas em ambiente escolar.

Para envolver o estudante, é necessário que o docente faça a transposição didática de forma adequada e também use diversas estratégias e recursos. Segundo Reginaldo, Sheid e Güllich (2012), a realização de experimentos, em ciências, representa uma excelente ferramenta para que o aluno faça a experimentação do conteúdo e possa estabelecer a dinâmica e indissociável relação entre teoria e prática, porém a maioria das escolas não possuem estruturas e nem recursos financeiros para realizar essas atividades práticas (Mota, 2019; Santana et al, 2019; Silva, Rocha \& Tchaicka, 2020; Tchaicka \& Reis, 2017).

Diante disto, realizamos entre os anos de 2011 e 2013 o projeto LABWICK Portas Abertas. O projeto foi idealizado 
por estudantes e professores do Curso de Ciências Biológicas da Universidade Estadual do Maranhão e buscou aproximar o Laboratório de Genética e Biologia Molecular Warwick Kerr - LABWICK, que se configura como espaço de pesquisas e produção de conhecimento científico biológico, dos estudantes e professores da rede básica de ensino da Ilha de São Luís, Maranhão. Através desta aproximação, buscamos compreender como os estudantes percebem e vivenciam as atividades práticas e/ou laboratoriais nas aulas de ciências em suas escolas e também a efetividade da uma visita ao LABWICK no contexto do ensino e aprendizagem de ciências e biologia.

\section{Metodologia}

Trata-se de um relato de experiência acerca de uma pesquisa-ação, pois os pesquisadores interagiram com os participantes do projeto, buscando mudanças em sua percepção (Koerich et al., 2009). O projeto contou com 3 etapas: o diagnóstico, a visita e a avaliação, tendo duração de dois anos, compreendendo o período de 2011 a 2013.

Os critérios adotados para a inclusão das escolas no projeto foram: 1. Localização na Ilha de São Luís - MA, englobando os municípios de São Luís, Paço do Lumiar, São José de Ribamar e Raposa; 2. Pertencer as redes de ensino particular ou pública do nível fundamental e médio. Foram escolhidos para participar do projeto os alunos do nono (fundamental) ao terceiro (médio) anos, pois compreendemos que os estudantes nesta fase já vivenciaram as possibilidades que a escola oferece.

Diagnóstico: Na primeira etapa, as escolas foram visitadas e os alunos que aceitaram participar do projeto responderam a um questionário prévio. O diagnóstico contou com 8 questões do tipo aberta que investigaram a existência e uso do laboratório pela escola, o entendimento sobre "aula prática" e o interesse por conhecer laboratórios. As informações objetivas obtidas através dos questionários foram plotadas no programa Microsoft Excel, e as repostas subjetivas foram organizadas em categorias (Minayo \& Sanches, 1993) e analisadas por meio de estatística descritiva., buscando identificar a percepção dos estudantes quanto às temáticas estudadas no LABWICK. Foram visitadas 12 escolas na ilha de São Luís para realização do diagnóstico prévio, sendo 6 de nível fundamental (3 públicas e 3 privadas) e 6 de nível médio (3 públicas e 3 privadas). Além da aplicação dos questionários, conversamos com pelo menos um professor de cada escola, que atua nas disciplinas de ciências (fundamental) e/ou biologia (médio). Também visitamos os espaços escolares para conhecer laboratórios, quando esses existiam.

Visita: Com base no diagnóstico, foram selecionados e desenvolvidos materiais paradidáticos e práticas laboratoriais adaptados ao público alvo com base em (Bonzanini \& Bastos, 2011; Fala, Correia \& Pereira, 2009; Justina \& Ferla, 2006; Leite, 2012; Martinez, Fujihara \& Martins, 2008). Os temas abordados foram: 1. Microscopia - a célula, o microscópio e cariótipo humano, utilizando impressões de cariótipos humanos normais e com síndrome de Down, e lâminas citogenéticas de roedores; 2. Vidrarias e equipamentos utilizados no dia a dia dos pesquisadores do LABWICK; 3. Material genético: extração de DNA da banana. Essas estratégias foram adotadas buscando realizar um ensino de ciências investigativo, que possibilita as interações entre sujeito e objeto de conhecimento (Zômpero \& Laburú, 2011).

O espaço utilizado na Universidade Estadual do Maranhão foi o LABWICK. Com área aproximada de 130m2 o LABWICK é utilizado para pesquisas que abordam a variabilidade genética em diferentes organismos silvestres. Desta fase participaram 9 escolas (4 turmas de nono ano fundamental, 5 turmas do ensino médio). Durante a visita, os estudantes assistiram a uma breve palestra mostrando o histórico sobre a descoberta do DNA e segurança laboratorial e logo após tiveram contato com as práticas experimentais. Para isto, cada turma recebida era dividida em dois grupos e encaminhados a setores diferentes do laboratório, um grupo ia para a sala de microscopia e o outro para a sala central do laboratório. Depois das atividades, os grupos trocavam de setor para observar e vivenciar os dois ambientes fornecidos pelo laboratório. No final da visita, foi disponibilizado para cada aluno um folder informativo detalhando os passos da extração de DNA da banana, onde 
estes poderiam realizar posteriormente na escola ou em suas próprias casas, promovendo assim, a transmissão dos conhecimentos adquiridos. Buscamos durante o percurso envolver ativamente os alunos em sua aprendizagem, por meio da geração de questões e problemas nos quais a investigação é condição para resolvê-los, com coleta, análise e interpretação de dados que levem a formulação e comunicação de conclusões baseadas em evidências e reflexão sobre o processo aumentando assim, a alfabetização científica (Melville et al., 2008; Scarpa \& Campos, 2018).

Avaliação e análise dos resultados: Ao final da visita, como última etapa, os estudantes responderam a um questionário que continha 8 perguntas, 4 abertas e 4 fechadas. As questões resgatavam os conteúdos explorados durante a visita e as percepções dos estudantes quanto a esse momento. As informações objetivas obtidas através dos questionários foram plotadas no programa Microsoft Excel, e as repostas subjetivas foram organizadas em categorias (Minayo \& Sanches, 1993) e analisadas por meio de estatística descritiva.

\section{Resultados e Discussão}

\section{Diagnóstico inicial}

Um total de 199 alunos participaram do diagnóstico prévio aplicado nas 12 escolas participantes desta etapa. Os estudantes possuíam idade variando entre 12 e 29 anos, e destes $83 \%$ pertencia à faixa etária de 15 a 17 anos. Eram em sua maioria do sexo feminino (58\%), e encontravam-se matriculados nas series do $9^{\circ}$ ano do ensino fundamental (15\%) e $1^{\mathrm{a}}(43 \%)$, $2^{\mathrm{a}}(14 \%)$ e $3^{\circ}(36 \%)$ séries do ensino médio.

Quanto à existência de um laboratório de Biologia/Ciências nas dependências da escola, 70\% dos alunos entrevistados negaram a inexistência do mesmo na instituição em que estuda, fato também observado pelos pesquisadores durante as visitas. E para aqueles que responderam positivamente, $93 \%$ destes alegaram que não era utilizado regularmente. Não foi constatada nenhuma diferença entre as escolas públicas e particulares em relação ao ensino prático de ciências/biologia, mostrando que as instituições participantes no cenário relatado por Borges (2002) que diz que o ensino através de metodologias práticas está cada vez mais em desuso e sugere novas alternativas para o ensino-prático de ciências.

Ao investigar o conhecimento dos alunos sobre o que seriam aulas práticas nas 12 escolas participantes (Figura 1), as respostas originaram 15 categorias: a categoria de conceito mais prevalente foi "Colocar em prática o que foi visto na teoria" (58), seguido de "Contato manual" (36). Assim, percebe-se que os alunos trazem consigo representações de uma ciência experimental e investigativa, muito difundida pela mídia. As outras representações menos frequentes associavam ao local em que a aula era ministrada, como: "aulas no laboratório" (10), "aulas fora da sala de aula" (4) e "aula na própria classe" (9). Outra categoria que chamou atenção foi "Não sabe, pois não tem laboratório ou nunca teve aulas práticas" correspondendo a 12 respostas. 
Figura 1: Definições elaboradas pelos estudantes do ensino básico de 12 escolas da Ilha de São Luís - MA para expressar a definição de "aulas práticas".

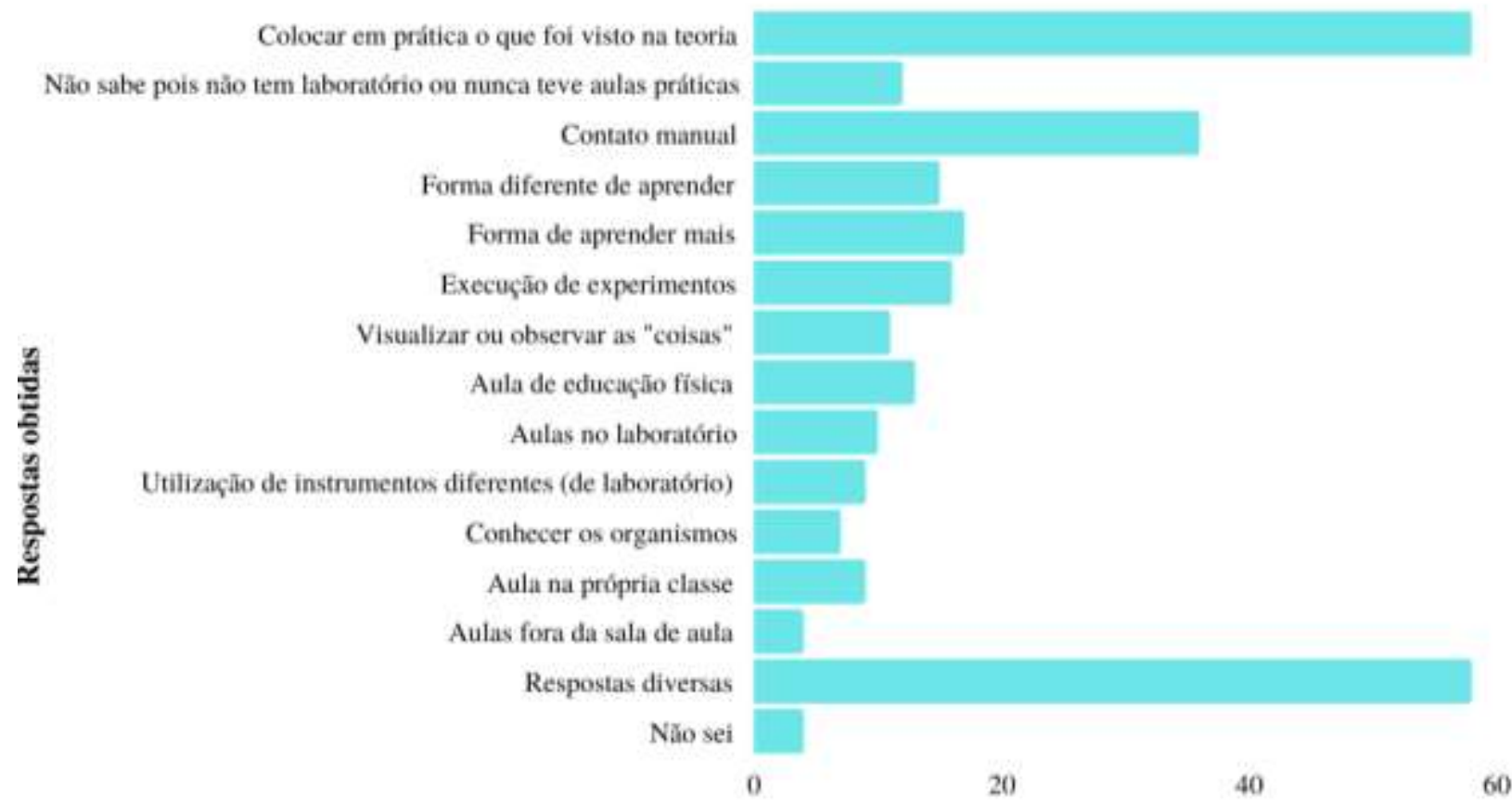

\section{Número de entrevistados}

Fonte: Autores (2021).

As aulas práticas no ensino de Biologia são indispensáveis no processo de alfabetização científica nas crianças e adolescentes tendo em vista que as atividades experimentais podem desencadear nos estudantes reflexões e inquietações sobre diversos fatos, fenômenos, principalmente em seu cotidiano e gerar, como consequência, que os alunos passem a raciocinar sobre o conhecimento científico, buscando conhecimento com maior entusiasmo e dedicação (Lima \& Garcia, 2011).

Além da ausência de laboratório no ambiente escolar, os professores afirmam não realizar a experimentação durante as aulas, por outros fatores que limitam a sua aplicação em sala de aula, como a falta de tempo devido a carga horária excessiva, o número elevado de alunos, falta de materiais e equipamentos, e até mesmo pelo despreparo em manusear os experimentos/equipamentos nessas atividades (Luz, Lima \& Amorim, 2018; Marandino, Selles \& Ferreira, 2009; Reginaldo, Sheid \& Güllich, 2012). Neste caso se aplica mais um fator importante para atividades de extensão universitárias voltadas a alunos do ensino médio e fundamental, pois além de levar a pratica aos alunos, professores podem tirar suas dúvidas e obter mais ideias e práticas com os experimentos.

Devido a esses empecilhos Garcia e Zanon (2021), sugerem que mudanças devem ser feitas dentro do sistema educacional para possibilitar aos professores a utilização de aulas experimentais. Por exemplo, reduzir o número de alunos por turmas para que os professores de Biologia possam desenvolver atividades práticas, bem como os docentes disporem de um tempo específico no planejamento das escolas para poder preparar não só atividades experimentais, mas também para rever e repensar sua prática docente, esses fatores irão contribuir também para o estimulo dos alunos na aprendizagem dos conteúdos.

Destaca-se ainda que a aula prática não é só aquela que acontece dentro do laboratório, ela pode ser uma demonstração experimental simples dentro da sala de aula, no pátio da escola, ou aulas de campo, sendo realizadas em ambientes externos, ou até mesmo nos arredores da escola. 
Sobre o interesse em visitar um laboratório de genética animal (Figura 2), dos 199 alunos, 57 responderam, "Sim, pois é uma forma de adquirir conhecimento", seguido de "Sim, por achar interessante" (24). As respostas negativas foram a minoria, com menos de $10 \%$. Tais repostas eram previsíveis, sabendo-se da estima que aulas práticas despertam, somado à frustração da falta de oportunidades de praticá-las.

Figura 2: Interesse dos estudantes do ensino básico de 12 escolas da Ilha de São Luís - MA em visitar um laboratório de genética animal.

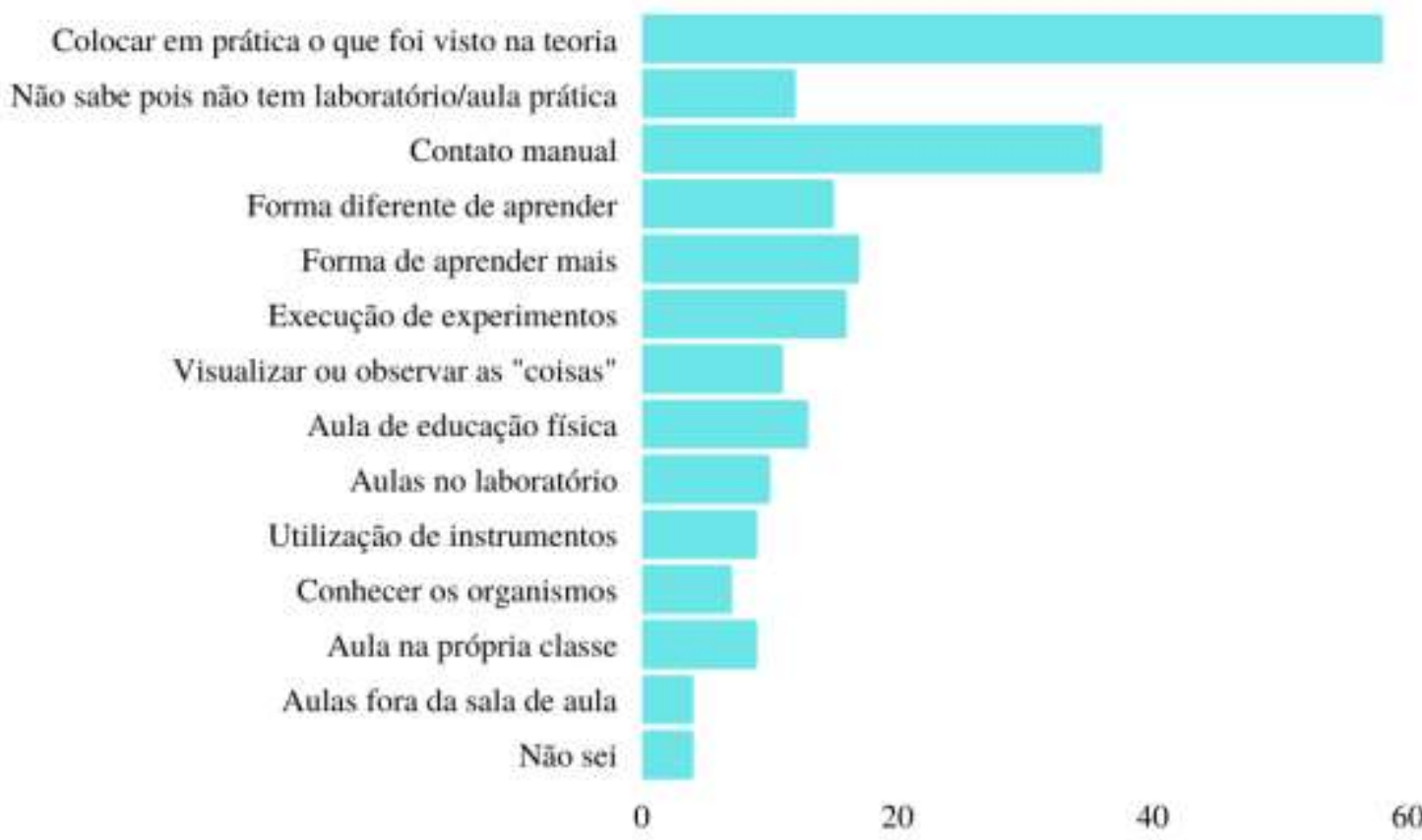

Número de entrevistados

Fonte: Autores (2021).

Um estudo realizado por Duré; Andrade; Abilio (2018), analisou os conteúdos de biologia que mais chamavam atenção dos alunos, e genética foi o terceiro conteúdo mais votado com $16 \%$, isso também foi mostrado por Malafaia, Bárbara e Rodrigues (2010) onde este foi o segundo conteúdo que despertava mais interesse entre os estudantes por estar relacionado a área da saúde. Evidenciando a importância de esclarecer e transmitir o conteúdo de forma que desperte ainda mais o interesse e a aprendizagem dos estudantes.

Segundo Duré, Andrade e Abilio (2018), é válido perceber que quanto mais abstrato e distante da realidade, maiores as chances de o estudante imaginar que está entendendo, sem de fato alcançar o entendimento real do que está sendo trabalhado na aula. Ao introduzir aulas práticas, modelos didáticos tridimensionais, vídeos e outros recursos, o professor leva o educando a confrontar o que achava que estava entendendo com o que de fato é realizando assim a transmissão do conteúdo de forma clara e realizando a compreensão correta pelos alunos.

Com isso, faz-se necessário que o docente de ciências tenha clara a importância de conhecer novos recursos, de desenvolver novas habilidades em termos de metodologias ativas, que passe a dominar as novas tecnologias disponíveis, de maneira a minimizar as dificuldades que são encontradas dentro da escola (Interaminense, 2019). 


\section{Visita ao laboratório e questionários pós visita}

Um total de 226 estudantes visitaram e participaram das atividades no LABWICK, e após o termino das práticas em laboratório foram submetidos a um questionário sobre os temas trabalhados.

Durante as visitas os alunos mostraram-se participantes, curiosos e atenderam aos pedidos e orientações da equipe do laboratório com atenção. Participaram ativamente na resposta das perguntas elencadas durante as práticas. Muitos relatavam que "estavam gostando muito de conhecer a universidade" e também "agora sei que eu também posso estudar aqui”.

Tais registros fortalecem a necessidade de que o meio científico busque aproximar-se da educação básica. Nesse sentido, grande responsabilidade é depositada nas universidades brasileiras, que devem investir esforços na transposição de barreiras que impedem a popularização dos conhecimentos gerados pela academia (Ferreira, 2005). Essa responsabilidade se materializa também na formação de professores, atores que tem o papel de influenciar os interesses dos jovens pela ciência.

Buscando diminuir as distâncias entre a geração do conhecimento científico e a divulgação científica, instituições brasileiras têm tomado iniciativas louváveis. Dentre as estratégias adotadas, temos o rádio, o contato entre a universidade e o ensino médio, assim como a informática, os museus de ciência, periódicos populares e outros, tem conquistado resultados significativos (Cavalcanti \& Persechini, 2011; Ferreira et al, 2005; Freitas Pinheiro \& Santos, 2019; Massarani \& Rocha, 2018; Paula, Pereira \& Coutinho, 2019; Porto, Oliveira \& Rosa, 2019).

Sobre a importância do uso de medidas de segurança no laboratório, um total de 96 alunos responderam "evitar acidentes", a "Proteção contra substâncias perigosas" (25) foi a segunda maior resposta, seguida de "Evitar danos à saúde" (19) (Figura 3).

Figura 3: Respostas sobre a importância de medidas de segurança em laboratórios elaboradas pelos estudantes do ensino básico de 9 escolas da Ilha de São Luís - MA que participaram da visita ao LABWICK.

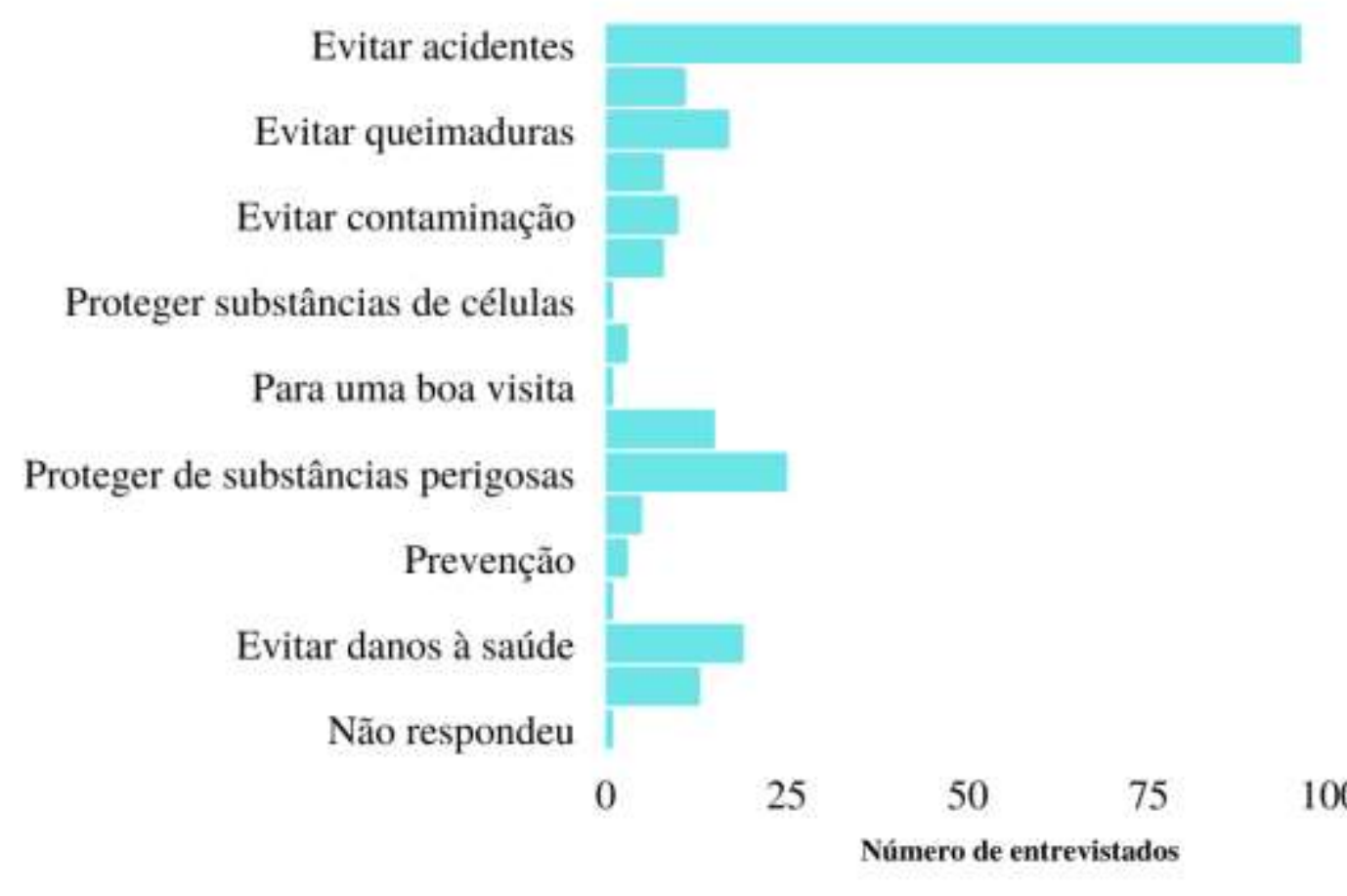

Fonte: Autores (2021).

É de extrema importância apresentar aos alunos os cuidados necessários em um laboratório, assim como, a importância e o uso adequado dos equipamentos de proteção individuais (EPI's) e dos equipamentos de proteção coletivos 
(EPC's), pois estes locais são considerados ambientes de risco potencial, principalmente as aulas que envolvem substâncias químicas tóxicas, material biológico, microbiológico. Segundo Sousa, Oliveira e Oliveira (2018), acidentes vêm ocorrendo nos ambientes de aulas práticas muitas vezes devido à ausência de orientações por parte do professor quanto aos riscos envolvidos em determinada aula.

Em relação à função do cariótipo, a principal resposta foi “Identificação ou diferenciação de espécies" (57). A segunda maior resposta foi "Identificação ou diferenciação de doenças" (40). As demais respostas foram todas corretas, demostrando assim que a prática favoreceu a compreensão do conteúdo (Figura 4).

Figura 4: Função da técnica de obtenção de cariótipos segundo os estudantes de 9 escolas da educação básica da Ilha de São Luís - MA que participaram das visitas ao LABWICK.

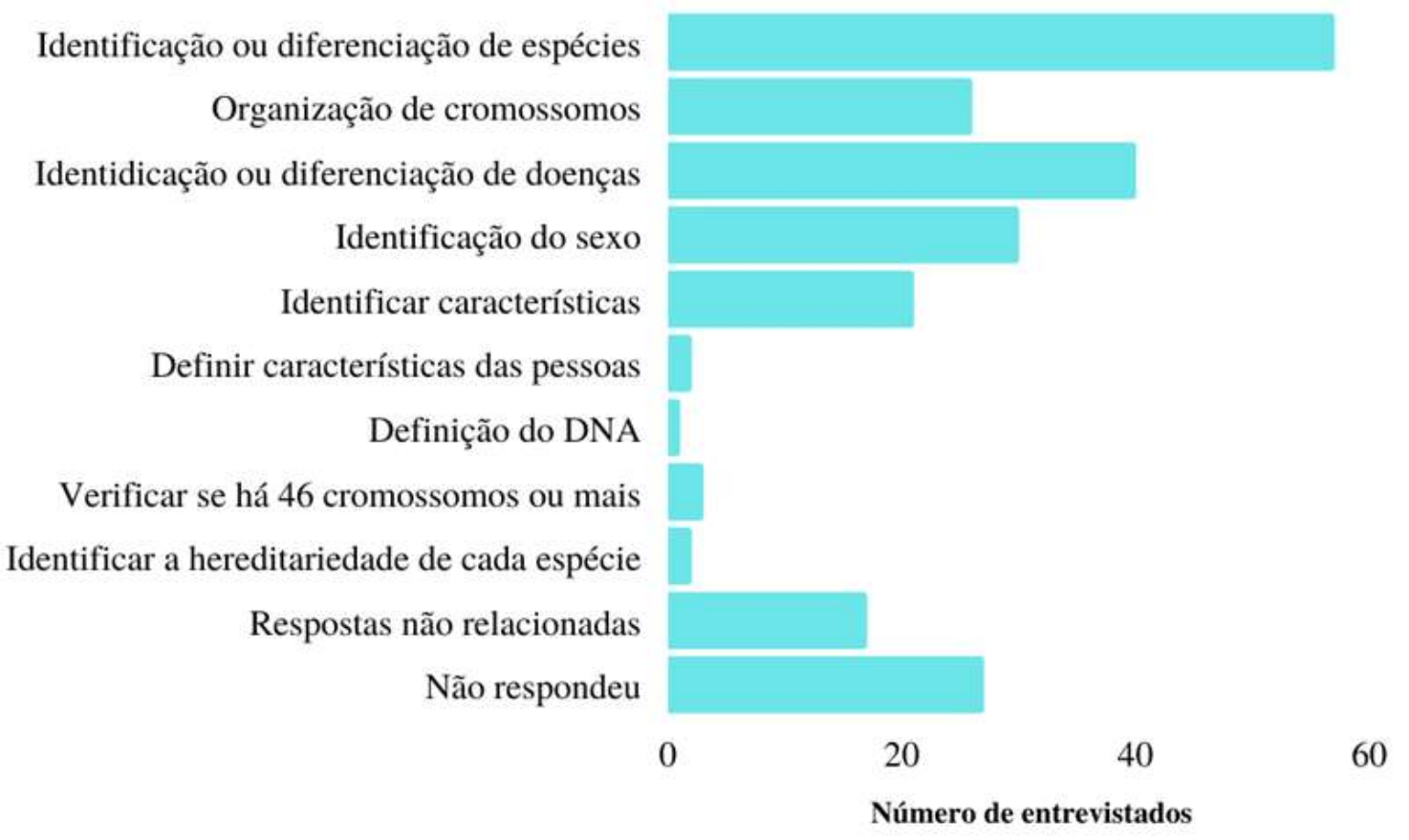

Fonte: Autores (2021).

Quando perguntados sobre o porquê da impossibilidade de visualizar a dupla hélice, os alunos responderam majoritariamente "Não se pode ver o DNA a olho nu” (26) e, em seguida, “o DNA pode ser visualizado em microscópio" (20). As categorias “O DNA pode ser visto quando a banana é descascada” (1), "É possível visualizar o DNA por um telescópio” (1) e "As células são muito pequenas" (1) obtiveram os mesmos níveis, sendo, inclusive, os que apresentaram uma resposta (Figura 5). Através das respostas obtidas, é possível verificar que alguns alunos ainda se confundem com alguns questionamentos sobre o tema abordado, assim como ocorreu na questão posterior (Figura 7), na qual foram apresentadas alternativas sobre a veracidade da função de substâncias na extração de DNA e os alunos marcaram como verídicas as seguintes respostas, respectivamente em ordem de importância: “O detergente é utilizado para romper a célula” (118), "O álcool deve ser gelado durante a extração de DNA para não dissolver o mesmo" (102) e "O DNA pode ser visualizado em microscópio eletrônico" (69). A alternativa menos votada como verdadeira foi "Pode-se extrair DNA sem retirá-lo da célula" (11) (Figura 6).

Esse tipo de dificuldade é comum nas aulas de genética ministradas para diferentes etapas do ensino (Arraes, 2016; 
Schineider et al, 2011), fazendo-se necessária a incorporação de mais de uma estratégia para abordar conteúdos complexos e abstratos da genética como o DNA e sua estrutura (Arraes, 2016; Nascimento et al, 20202; Silva et al, 2021).

Figura 5: Percepções dos estudantes de 9 escolas da educação básica da Ilha de São Luís - MA sobre a possibilidade de visualizar o DNA após visita ao LABWICK.

Não se pode ver o DNA a olho nu

Nầo é possível ver DNA no microscópio

O DNA pode ser visto quando a banana é descascada

O DNA pode ser visualizado no microscópio

O DNA é muito pequeno

Ê possível visualizar DNA por um telescópio

O DNA só pode ser visualizado com álcool e detergente

A dupla hélice é muito pequena

Porque não há microscópio eletrônico

É possível ver a dupla hélice no mícroscópio

As células são muito pequenas

Não respondeu

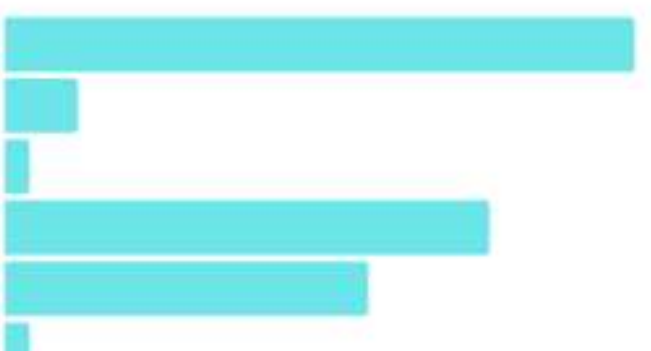

$\begin{array}{llll}0 & 10 & 20 & 30\end{array}$

Número de entrevistados

Fonte: Autores (2021).

Figura 6: Informações indicadas como verdadeiras sobre a extração de DNA segundo os estudantes de 9 escolas da educação básica da Ilha de São Luís - MA após visita ao LABWICK.

O álcool deve ser gelado para facilitar o isolamento

O DNA pode ser visualizado em microscópio eletrônico

Pode -se extrair DNA sem retirá-lo da célula

O detergente é utilizado para romper a célula

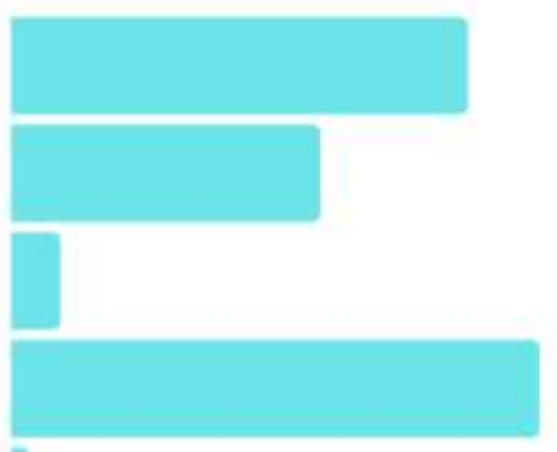

Não respondeu

$\begin{array}{llllll}0 & 25 & 50 & 75 & 100 & 125\end{array}$

Número de entrevistados

Fonte: Autores (2021). 
No contexto geral, percebe-se que alunos compreenderam o que eles observaram nas diferentes aulas práticas e esse fato reafirma a importância da presença de aulas experimentais e de campo durante o período escolar. Lima e Garcia (2011) relatam que aulas práticas diferentes e inovadoras motivam os estudantes a pensarem e construírem conhecimento, e que estas podem ser feitas em diversos locais e momentos, o simples fato deles estarem em um ambiente diferente da sala de aula convencional, estimula a aprendizagem dos conteúdos.

Os questionamentos sobre os conteúdos abordados despertam o interesse investigativo e geram motivação em participar de todas as etapas do processo experimental, tornando-se uma ferramenta de ensino rica, possibilitando criar situações que venham a motivar os alunos. Segundo Krasilchik (2004), quando a aula prática se resume a mera reprodução de um roteiro, ela é considerada uma simples atividade manual, logo, é necessário que os alunos se deparem com problemas a serem resolvidos a partir da reflexão e da discussão em grupo. Nesses momentos o aluno pode demonstrar suas habilidades de manipulação ou de interpretação que antes não eram requisitadas na aula tradicional. Por fim, os estudantes que tiveram a oportunidade de visitar o laboratório saíram de lá com novas perspectivas quanto a sua carreira estudantil e posteriormente acadêmica.

\section{Conclusão}

Pelo depoimento dos alunos pode-se notar que poucas escolas ainda mantêm laboratórios e que quando esses espaços existem, há carência de utilização. De forma geral, não são utilizadas as atividades práticas no ensino de ciências e biologia nas escolas. Os estudantes, no entanto, relacionam essa metodologia com um aprendizado mais eficiente. Pode-se constatar que os estudantes que visitaram o LABWICK envolveram-se com as atividades e assimilaram as informações. A experiência mostrouse válida ao aproximar os alunos do ensino básico da universidade, contribuindo para a popularização da ciência e o despertar da curiosidade e interesse dos estudantes, bem como da efetivação do papel da universidade junto à comunidade. Indicamos que é necessário que o docente de ciências tenha clara a importância de conhecer novos recursos, de desenvolver novas habilidades em termos de metodologias ativas, que passe a dominar as novas tecnologias disponíveis, de maneira a minimizar as dificuldades que pairam sobre as escolas brasileiras.

\section{Referências}

Arraes, B. (2016) Percepção e assimilação dos alunos do primeiro semestre de medicina frente á atividade prática de extração do dna da banana no módulo de biologia celular e molecular. VI Encontro de Projetos de Monitoria da Graduação da UFC. Fortaleza, CE.

Bonzanini, T. K., \& Bastos, F. (2011, dezembro). Temas da Genética contemporânea e o Ensino de Ciências: que materiais são produzidos pelas pesquisas e que materiais os professores utilizam. VIII ENPEC- Encontro Nacional do Ensino de Ciências, Campinas, SP, Brasil.

Borges, A. T. (2002). Novos rumos para o laboratório escolar de ciências. Caderno Brasileiro de ensino de Física, 19(3), $291-313$.

Cavalcanti, C. C., \& Persechini, P. M. (2011). Museus de Ciência e a popularização do conhecimento no Brasil. Field Actions Science Reports. The journal of field actions, (Special Issue 3).

Duré, R. C., de Andrade, M. J. D. \& Abílio, F. J. P. (2018). Ensino de biologia e contextualização do conteúdo: quais temas o aluno de ensino médio relaciona com o seu cotidiano? Experiências em ensino de ciências, 13(1), 259-272.

Fala, A. M., Correia, E. M., \& Pereira, H. D. M. (2009). Atividades práticas no ensino médio: uma abordagem experimental para aulas de genética. Ciências \& Cognição, 15(1), pp. 100-123.

Ferreira, A. V. B. F., Malagoli, B. G., Reis, D. A., Lima, E. G., \& Antonio, H. (2005, outubro). O Rádio Como Veículo De Extensão Universitária: Uma Experiência do Instituto de Ciências Biológicas na Popularização do Conhecimento Científico. Anais do 8 Encontro de Extensão da UFMG. Belo Horizonte MG, Brasil,8.

Freitas Pinheiro, M. T., \& Santos, L. M. (2019). Reflexões sobre o ensino de ciências frente os desafios da cibercultura. Boletim GEPEM, (75), 89-103.

Garcia, R. A. G., \& Zanon, A. M. (2021). Aulas experimentais de biologia: um diálogo com professores e alunos. Instrumento: Revista de Estudo e Pesquisa em Educação, 23(1), 42-62.

Germano, M. G., \& Kulesza, W. A. (2007). Popularização da ciência: uma revisão conceitual. Caderno Brasileiro de ensino de Física, $24(1)$, 7-25. 
Interaminense, B. D. K. S. (2019). A Importância das aulas práticas no ensino da Biologia: Uma Metodologia Interativa/The Importance of practical lessons in the teaching of Biology: An Interactive Methodology. ID on line Revista De Psicologia, 13(45), 342-354.

Justina, L. A. D., \& Ferla, M. R. (2006). A utilização de modelos didáticos no ensino de genética-exemplo de representação de compactação do DNA eucarioto. Arquivos do MUDI, 10(2), 35-40.

Koerich, M. S., Backes, D. S., de Sousa, F. G. M., Erdmann, A. L., \& Alburquerque, G. L. (2009). Pesquisa-ação: ferramenta metodológica para a pesquisa qualitativa. Revista Eletrônica de Enfermagem, 11(3).

Leite, S. Q. M. (2012). Práticas experimentais investigativas em ensino de ciências: caderno de experimentos de física, química e biologia-espaços de educação não formal-reflexões sobre o ensino de ciências. Editora do Instituto Federal de Educação. Ciência e Tecnologia do Espírito Santo.

Lima, D. B., \& Garcia, R. N. (2011). Uma investigação sobre a importância das aulas práticas de Biologia no Ensino Médio. Cadernos do Aplicação, 24(1),203-223.

Luz, P. S., de Lima, J. F., \& Amorim, T. V. (2018). Aulas práticas para o ensino de Biologia: contribuições e limitações no Ensino Médio. Revista de Ensino de Biologia da SBEnBio, 36-54.

Malafaia, G., Bárbara, V. F., \& de Lima Rodrigues, A. S. (2010). Análise das concepções e opiniões de discentes sobre o ensino da biologia. Revista Eletrônica de Educação, 4(2), 165-182.

Marandino, M., Selles, S. E., \& Ferreira, M. S. (2009). Ensino de Biologia: histórias e práticas em diferentes espaços educativos. Editora Cortez.

Martinez, E. R. M., Fujihara, R. T., \& Martins, C. (2008). Show da Genética: um jogo interativo para o ensino de genética. Genética na escola, 3(2), $24-27$.

Massarani, L., \& Rocha, M. (2018). Ciência e mídia como campo de estudo: uma análise da produção científica brasileira. Intercom: Revista Brasileira de Ciências da Comunicação, 41, 33-49.

Melville, W., Fazio, X., Bartley, A., \& Jones, D. (2008). Experience and reflection: Preservice science teachers' capacity for teaching inquiry. Journal of Science Teacher Education, 19(5), 477-494.

Minayo, M. C. D. S., \& Sanches, O. (1993). Quantitativo-qualitativo: oposição ou complementaridade? Cadernos de saúde pública, 9, 237-248.

Mota, M. D. A. (2019). Laboratórios de ciências/biologia nas escolas públicas do estado do Ceará (1997-2017): realizações e desafios. (Dissertação de mestrado). Universidade Federal do Ceará -UFC, Fortaleza, CE, Brasil.

Nascimento, R. G. et al. (2020). Prática lúdica 'DNA recombinante' e sua influência na percepção e no conhecimento de estudantes sobre biotecnologia e enzimas de restrição. Experiências em Ensino de Ciências, 15(20), 262-282

Paula, L. M. D., Pereira, G. R., \& Coutinho-Silva, R. (2019). A Função social dos museus e centros de ciências: integração com escolas e secretarias de educação. Ciência e Cultura, 71(2), 04-05.

Persechini, P. M., \& Cavalcanti, C. (2004). Popularização da ciência no Brasil. Jornal da Ciência, (535).

Porto, C., Oliveira, K. E., \& Rosa, F. (2018). Produção e difusão de ciência na cibercultura: narrativas em múltiplos olhares. Editora Editus.

Reginaldo, C. C., Sheid, N. J., \& Güllich, R. I. D. C. (2012, julho). O ensino de ciências e a experimentação. Anaped Sul: Seminário de Pesquisa em Educação da Região Sul, Giruá, Caxias do Sul, RS, Brasil, 9.

Santana, S. D. L. C., Pessano, E. F. C., Escoto, D. F., da Cruz Pereira, G., Gularte, C. A. O., \& Folmer, V. (2019). O ensino de ciências e os laboratórios escolares no Ensino Fundamental. VITTALLE-Revista de Ciências da Saúde, 31(1), 15-26.

Sasseron, L. H., \& de Carvalho, A. M. P. (2016). Alfabetização científica: uma revisão bibliográfica. Investigações em ensino de ciências, $16(1), 59-77$.

Scarpa, D. L., \& Campos, N. F. (2018). Potencialidades do ensino de Biologia por Investigação. Estudos avançados, 32 , $25-41$.

Schneider, E. M., Justina, L. A. D., \& Meglhioratti, F. A. (2011). A percepção de alunos do ensino médio em relação a interação gene-organismo-ambiente. In: VIII ENPEC - Encontro Nacional de Pesquisa em Educação em Ciências e I CIEC - Congreso Iberoamericano de Investigacion en Ensenanza de las Ciencias.

Silva, A. I. F., Rocha, E. C., \& Tchaicka, L. (2020). O animal preferido nos desenhos infantis e sua relação com a conservação da fauna. Brazilian Journal of Development, 6(7), 47590-47603.

Silva et al. (2021). Modelos didáticos de DNA no ensino de genética: experiência com estudantes do ensino médio em uma escola pública do Piauí. Research, Society and Development, 10(2).

Souza, R. A., Oliveira, F. Q., \& Oliveira, E. M. (2018). A importância da gestão de risco em laboratórios de aula prática de instituições de ensino superior. Revista Brasileira de Ciências da Vida, 6.

Tchaicka, L., \& Reis, R. (2017). Das moléculas aos ecossistemas: Experimentando a pesquisa em genética e conservação no ensino médio. Editora: UEMAnet.

Zômpero, A. F., \& Laburú, C. E. (2011). Atividades investigativas no ensino de ciências: aspectos históricos e diferentes abordagens. Ensaio Pesquisa em Educação em Ciências, 13(3), 67-80. 